DOI: 10.1515/plass-2017-0016

Marta Brylińska*, Jadwiga Śliwka

Plant Breeding and Acclimatization Institute - National Research Institute, Młochów

Research Center, Platanowa Str. 19, 05-831 Młochów, Poland;

*Corresponding author: m.brylinska@ihar.edu.pl

\title{
LABORATORY ASSESSMENT OF POTATO RESISTANCE \\ TO PHYTOPHTHORA INFESTANS
}

\begin{abstract}
Resistance breeding is a very important alternative to chemical control of late blight. Many resistance $(R)$ genes from the wild Solanum species have been discovered and introduced into the cultivated potato. The laboratory methods to assess the resistance to late blight such as tests on detached leaflets, leaves, tuber slices, or whole tubers, are easy, cheap, fast and provide a good estimation of resistance that can be further confirmed in field trials for the selected material. Laboratory assessment is particularly useful for materials, in which major resistance genes segregate and the resistance is qualitative rather than quantitative.
\end{abstract}

Key words: detached leaflet test, late blight, leaf test, Solanum, tuber tests

\section{INTRODUCTION}

Late blight is economically the most important potato disease that is currently managed by intensive chemical control. Growing late blight resistant cultivars could reduce fungicide inputs, and, in turn, it would lower the cost and the negative impact of potato production on the environment. The first genes conferring race-specific resistance to $P$. infestans, $R 1-R 11$, were discovered in S. demissum (Black et al., 1953; Malcolmson and Black, 1966). To date, over $60 R$ genes have been identified from different wild Solanum species e. g. S. berthaultii, S. bulbocastanum, S. microdontum, S. mochiquense, S. phureja, S. pinnatisectum, S. ruiz-ceballosii, S. sparsipilum, S. spegazzinii, S. stoloniferum, S. verrucosum (Rodewald and Trognitz, 2013). Some of these genes were used in potato breeding programs and have been introduced by crossing and backcrossing into the cultivated potato, for example cultivars: Pentland

Communicated by Ewa Zimnoch-Guzowska 
Dell with genes $R 1, R 2, R 3$, (Malcolmson, 1969), Epoka - R3, R4, (Rudkiewicz, 1985), Bzura - R2-like (Plich et al., 2015) from S. demissum, and Toluca - Rpi-blb2, Biogold - Rpi-abpt from S. bulbocastanum (van der Vossen et al., 2003). New strains of $P$. infestans are able to overcome the $R$ gene-conferred resistance. One of the strategies for obtaining durable and broad spectrum resistance against late blight is $R$ gene pyramiding (Haverkort et al., 2009).

Assessing resistance to late blight in laboratory tests, despite giving only a rough estimation of the performance in nature, is cheaper than the field tests and allows fast and relatively easy scoring of many plant genotypes. In laboratory tests the conditions are controlled, the applied $P$. infestans isolate is defined and characterized. In the containment, it is possible to use isolates which are not present in the natural population in a given country, either anticipating $P$. infestans migration or predicting the potato genotype resistance in other geographic regions. What is also important in the changing climate, laboratory tests can be performed independently of weather conditions in the field and high disease pressure can be obtained whenever needed. The semiquantitative character of scoring in laboratory tests makes them particularly suitable for assessment of $R$ gene segregation in mapping populations (Śliwka et al., 2006; Śliwka et al., 2012a; Tomczyńska et al., 2014) or preliminary screenings for resistance in germplasm collections (Zoteyeva et al., 2012). The number of tested leaflets, tubers or tuber slices per replication per potato genotype as well as the number of replication may vary depending on the research question and the type of resistance present in the material. The numbers proposed below have been used in published works (Śliwka et al., 2006; Śliwka et al., 2012a; Tomczyńska et al., 2014). Each experiment should be performed at least twice, preferably on different dates, using an independently prepared inoculum. The quality and viability of the inoculum may affect the test strength. The growing conditions of the plant materials may also affect the results of the resistance tests, especially when plants are grown in the field, and thus repeating the test in different growing seasons is recommended.

The detached leaflet test (Photo 1) was first conducted to test the resistance of potato genotypes in the Netherlands by Toxopeus (1954). The method described here is based on the work of Lapwood (1963) and Zarzycka (2001a). The detached leaf test (Photo 2) is adopted from Kuhl et al. (2001). This test is dedicated to testing the wild potato species, which have thin and small leaflets, such as $S$. pinnatisectum (Kuhl et al., 2001) or S. michoacanum (Śliwka et al., 2012b; Smyda-Dajmund et al., 2017). The tuber slice test was developed by Lapwood (1965), modified and described by Zarzycka (1990 and 2001b). The whole tuber test is based on the method described by Bjor (1987). The previous data indicate that the tuber slice and whole tuber tests should be performed between the $16^{\text {th }}$ and $28^{\text {th }}$ week after planting the tuber because the resistance is the most stable at this time and the tubers are already mature but not too old for testing (Lebecka et al., 2006).

\section{MATERIALS}

1) Inoculum of $P$. infestans prepared as described by Sobkowiak and Śliwka (2017)

2) Pipette tips 
3) Leaflets of susceptible and resistant standard cultivars

4) Tubers of susceptible and resistant standard cultivars

5) Wet paper

EQUIPMENT
1) Pipettes
2) Sprayer
3) Knife
4) Instrument with 16 pins
5) Plastic trays
6) Glass covers

PROCEDURE

\section{Standards and virulence}

Regardless of the test type it is recommended to use susceptible and resistant standard cultivars, for example a set proposed by the EUCABLIGHT (www.euroblight.net). These standards should be treated and prepared in the same way as the tested potato genotypes. For each $P$. infestans isolate used in the tests, the virulence should be evaluated in parallel to the test on the leaflets of Black's differentials and the differentials with the new $R$ genes (Zhu et al., 2015).

\section{The detached leaflet and leaf assays}

1) Preparation of the leaflets/leaves:

a) 3-5 fully-expanded lateral leaflets or 1-2 leaves are collected from the middle part of potato plants in two replicates from 6-week-old plants of each tested potato genotype.

b) The leaflets/leaves are placed on wet paper the abaxial side up in plastic trays.

c) The plastic trays with the leaflets/leaves are covered with glass.

2) Inoculation of leaflets:

a) A $30 \mu 1$ drop of a sporangia suspension of a concentration of 50 sporangia $\times \mu l^{-1}$ is placed near the midrib on each leaflet.

3) Inoculation of leaves:

a) The leaves are sprayed with a sporangia suspension of a concentration of 50 sporangia $\times \mu \mathrm{l}^{-1}$. The spray nozzle should be $\sim 30 \mathrm{~cm}$ away from the plastic tray. The inoculum must be stirred by shaking the sprinkler.

4) Incubation:

a) The inoculated leaflets/leaves are incubated at $16^{\circ} \mathrm{C}$ in the dark and in high humidity conditions ( $>80 \% \mathrm{RH})$.

b) The following day the leaflets/leaves are turned over, the adaxial side up, and constant light of about $1600 \mathrm{~lx}$ is switched on. De- 
tached leaflets and leaves with disease symptoms after incubation are shown in Photo 1 and 2, respectively.

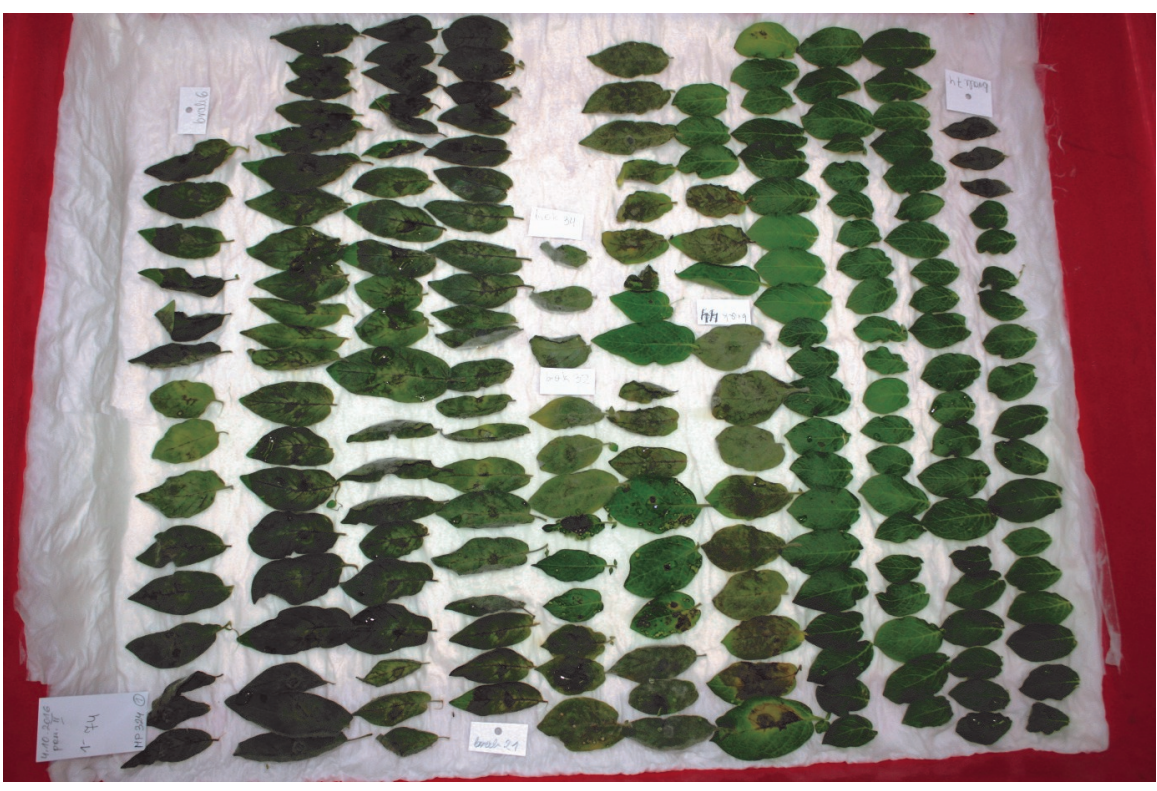

Photo 1. A detached leaflet assay (photographed by M. Brylińska). Late blight symptoms six days after inoculation.

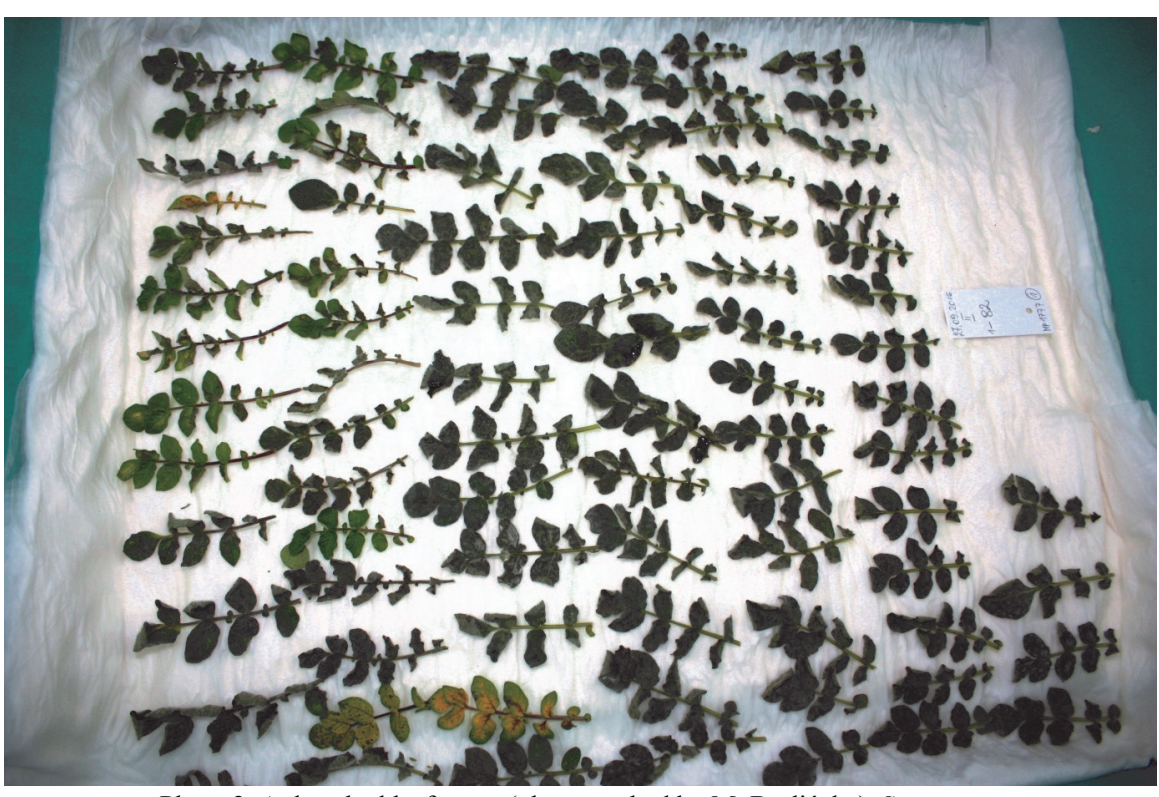

Photo 2. A detached leaf assay (photographed by M. Brylińska). Symptoms of late blight after six days of incubation. 


\section{Tuber slice test}

1) Preparation of the slices:

a) For each potato genotype undergoing testing, two replicates of between three and ten double slices, each $10 \mathrm{~mm}$ thick (the two slices are connected by a fragment (ca. 20\%) of the tuber which is not cut) are cut out from the middle part of the tubers and placed in plastic trays.

2) Inoculation and incubation:

a) A drop of $30 \mu 1$ of the inoculum with a concentration of 50 sporangia $\times \mu l^{-1}$ is introduced between the double slices with a pipette.

b) The plastic trays with the tuber slices are placed at $16^{\circ} \mathrm{C}$ in the dark and covered with glass.

\section{Whole tuber test}

1) Preparation of the tubers:

a) Five to ten tubers of each genotype in two replicates are placed in plastic trays and wounded on the apical end by pressing with 16 pins placed on an area of $12 \times 12 \mathrm{~mm}$. The tubers are wounded ca. $2 \mathrm{~mm}$ deep.

b) The prepared tubers are kept at $16^{\circ} \mathrm{C}$ in the dark for $24 \mathrm{~h}$.

2) Inoculation and incubation:

a) The tubers are sprayed with an inoculum of a concentration of 50 sporangia $\times \mu 1^{-1}$. The spray nozzle should be $\sim 30 \mathrm{~cm}$ away from the plastic tray.

b) The tubers in the plastic trays are incubated at $16^{\circ} \mathrm{C}$ in the dark.

\section{Scoring}

Scoring is usually conducted after six (the detached leaflet/leaf and tuber slice tests) or fourteen (the whole tuber test) days of incubation. The time of scoring may be adjusted according to the development of the disease symptoms on standard cultivars or the tested material and it can be done earlier or later than six days after inoculation, when the progress of the disease is faster or slower than expected. In the whole leaf tests, up to 6 lateral leaflets are scored per leaf, each leaflet separately. The whole tubers are cut in halves, longitudinally through the wounding site. Scoring is performed on a 1-9 scale, where 9 means no disease symptoms or non-sporulating hypersensitivity necroses not exceeding the inoculation droplet/site in size. Leaflets, tuber slices or internal cut surfaces of whole tubers scored as 1 are covered in $100 \%$ with the disease lesion. It is challenging to score the intermediate states with scores 2-8 reliably, and to relate the scores to the percentage of the diseased surface as described by Zarzycka (2001a,b). The photographs illustrating the scale for leaflets, tuber slices and whole tubers are used to improve scoring standardization (Sobkowiak et al., 2012). When scoring detached leaflets and tuber slices, the intensity of sporulation on the infected area is taken into account: scores 8-7 showing weak sporulation, scores 6-3 with intense sporulation and scores 1-2 with very intense sporulation. 


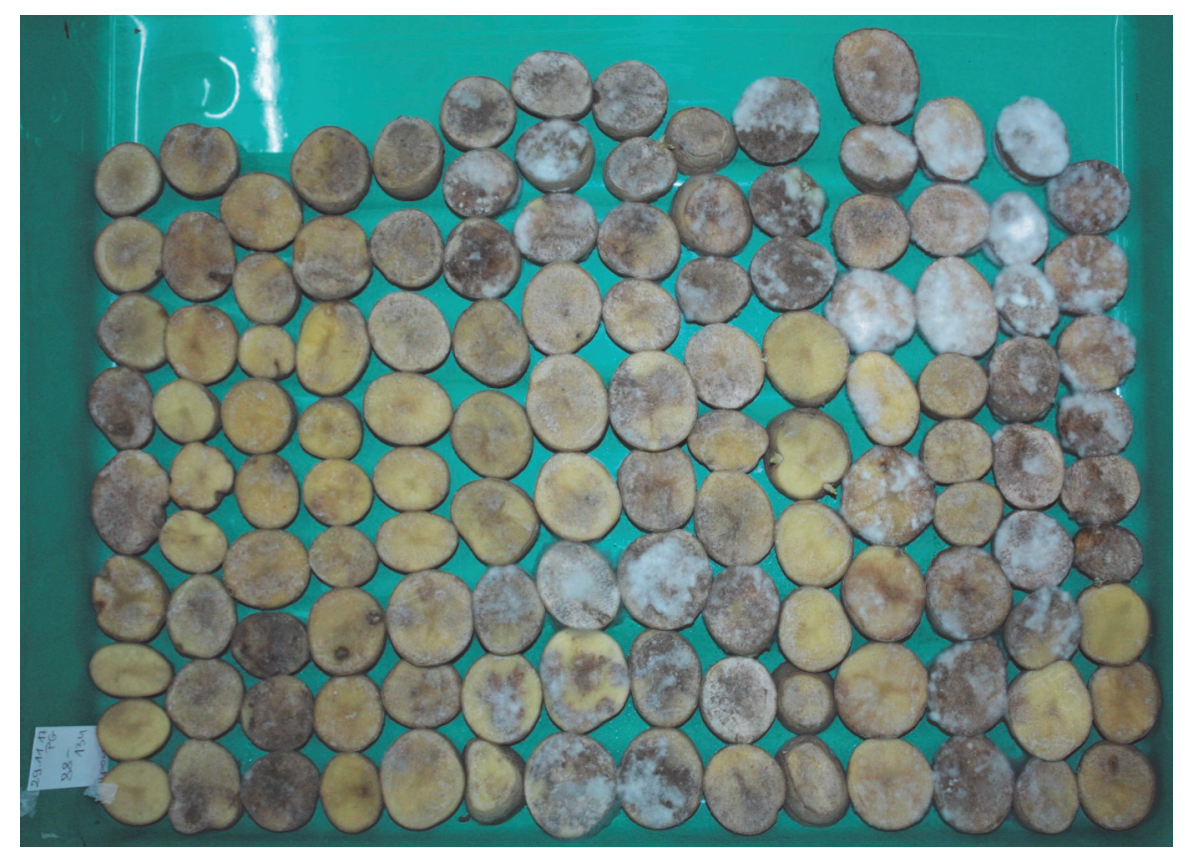

Photo 3. Tuber slice assay (photographed by M. Brylińska). Symptoms of late blight disease six days post inoculation.

\section{ACKNOWLEDGMENTS}

This work was carried out as part of the statutory project No 1-3-00-3-06 of the Plant Breeding and Acclimatization Institute - National Research Institute.

\section{REFERENCES}

Bjor T. 1987. Testing the resistance of potato genotypes to tuber late blight. Potato Res. 30: 525-532.

Black W., Mastenbroek C., Mills W.R., Peterson L.C. 1953. A proposal for an international nomenclature of races of Phytophthora infestans and of genes controlling immunity in Solanum demissum derivatives. Euphytica 2: 173-178.

Haverkort A.J., Struik P.C., Visser R.G., Jacobsen E. 2009. Applied biotechnology to combat late blight in potato caused by Phytophthora infestans. Potato Res. 52: 249-264.

Kuhl J.C., Hanneman R.E., Havey M.J. 2001. Characterization and mapping of Rpil, a late blight resistance locus from diploid (1EBN) Mexican Solanum pinnatisectum. Mol. Genet. Genomics 265: 977-985.

Lapwood D.H. 1963. Potato haulm resistance to Phytophthora infestans. IV. Laboratory and field estimates compared and further field analysis. Ann. Appl. Biol. 51: 17-28.

Lebecka R., Sobkowiak S., Zimnoch-Guzowska E. 2006. Resistance of potato tubers to a highly aggressive isolate of Phytophthora infestans in relation to tuber age. Potato Res. 49: 99-107.

Malcolmson J.F., Black W. 1966. New $R$ genes in Solanum demissum Lindl. And their complementary races of Phytophthora infestans (Mont.) de Bary. Euphytica 15: 199-203.

Malcolmson J.F. 1969. Races of Phytophthora infestans occurring in Great Britain. T. Brit. Mycol. Soc 53: $417-423$.

Plich J., Tatarowska B., Lebecka R., Śliwka J., Zimnoch-Guzowska E., Flis B. 2015. R2-like gene contributes to resistance to Phytophthora infestans in Polish potato cultivar Bzura. Am. J. Potato Res. 92(3): 350 358. 
Rodewald J., Trognitz B. 2013. Solanum resistance genes against Phytophthora infestans and their corresponding avirulence genes. Mol.. Plant Pathol. 14(7): 740-757.

Rudkiewicz F. 1985. Zaraza ziemniaka (Phytophthora infestans (Mont.) de Bary). In: Gabriel W. (ed.), Biologia Ziemniaka Państwowe Wydawnictwo Naukowe. Warsaw, Poland.

Smyda-Dajmund P., Śliwka J., Wasilewicz-Flis I., Jakuczun H., Zimnoch-Guzowska E. 2017. BC1 and F1 progeny from Solanum $\times$ michoacanum $(+) S$. tuberosum somatic hybrids, autofused $4 x$ S. michoacanum and cultivated potato. Am. J. Potato Res. 94(4): 323-333.

Sobkowiak S., Śliwka J. 2017. Phytophthora infestans: isolation of pure cultures, storage and inoculum preparation. Plant Breed. Seed Sci., 76: 9-15

Sobkowiak S., Zarzycka H., Śliwka J. 2012. Laboratoryjne metody oceny odporności ziemniaka na Phytophthora infestans. Ziemniak Polski 3: 3-8.

Śliwka J., Jakuczun H., Lebecka R., Marczewski W., Gebhardt C., Zimnoch-Guzowska E. 2006. The novel, major locus Rpi-phul for late blight resistance maps to potato chromosome IX and is not correlated with long vegetation period. Theor. Appl. Genet. 113: 685-695.

Śliwka J., Jakuczun H., Chmielarz M., Hara-Skrzypiec A., Tomczyńska I., Kilian A., Zimnoch-Guzowska E. 2012a. Late blight resistance gene from Solanum ruiz-ceballosii is located on potato chromosome $\mathrm{X}$ and linked to violet flower colour. BMC Genetics 13: 11

Śliwka J., Jakuczun H., Chmielarz M., Hara-Skrzypiec A., Tomczyńska I., Kilian A., Zimnoch-Guzowska E. 2012 b. A resistance gene against potato late blight originating from Solanum $\times$ michoacanum maps to potato chromosome VII. Theor. Appl. Genet. 124: 397-406.

Tomczyńska I., Stefańczyk E., Chmielarz M., Karasiewicz B., Kamiński P., Jones J.D.G., Lees A.K., Śliwka J. 2014. A locus conferring effective late blight resistance in potato cultivar Sárpo Mira maps to chromosome XI. Theor. Appl. Genet. 127: 647-657.

Toxopeus H.J. 1954. Leaf testing as a method of genetical analysis of immunity from Phytophthora infestans in potatoes. Euphytica 3: 233-240.

van der Vossen E., Sikkema A., Hekkert B. L., Cros J., Stevens P., Muskens M., Wouters D., Pereira A., Stiekema W., Allefs S. 2003. An ancient $R$ gene from the wild potato species Solanum bulbocastanum confers broad-spectrum resistance to Phytophthora infestans in cultivated potato and tomato. The Plant Journal 36: $867-882$

Zarzycka H. 1990. Comparison of the tuber slice and whole tuber test used for assessment of potato resistance to tuber blight (Phytophthora infestans/ Mont./ de Bary). Acta Agrobot. 43: 95-107.

Zarzycka H. 2001a. Evaluation of resistance to Phytophthora infestans in detached leaflet assay. Preparation of the inoculum. Monografie i Rozprawy Naukowe IHAR Radzików 10: 77-79.

Zarzycka H. 2001b. Assessment of resistance to Phytophthora infestans in tuber slices and in whole tubers. Monografie i Rozprawy Naukowe IHAR Radzików 10: 78-80.

Zhu S.X., Vossen J.H., Bergervoet M., Nijenhuis M., Kodde L., Kessel G.J.T., Vleeshouwers V., Visser R.G.F., Jacobsen E. 2015. An updated conventional-and a novel GM potato late blight R gene differential set for virulence monitoring of Phytophthora infestans. Euphytica 202: 219-234.

Zoteyeva N., Chrzanowska M., Flis B., Zimnoch-Guzowska E. 2012. Resistance to pathogens of the potato accessions from the collection of N.I. Vavilov Institute of Plant Industry (VIR). Am. J. Potato Res. 89: $277-293$ 